\title{
Convergence of Spinal Trigeminal and Cochlear Nucleus Projections in the Inferior Colliculus of the Guinea Pig
}

\author{
JIANXUN ZHOU AND SUSAN SHORE* \\ Kresge Hearing Research Institute, Department of Otolaryngology, University of \\ Michigan, Ann Arbor, Michigan 48109-0506
}

\begin{abstract}
In addition to ascending auditory inputs, the external cortex of the inferior colliculus (ICX) receives prominent somatosensory inputs. To elucidate the extent of interaction between auditory and somatosensory representations at the level of IC, we explored the dual projections from the cochlear nucleus $(\mathrm{CN})$ and the spinal trigeminal nucleus (Sp5) to the inferior colliculus (IC) in the guinea pig, using both retrograde and anterograde tracing techniques. Injections of retrograde tracers into ICX resulted in cell-labeling primarily in the contralateral DCN and pars interpolaris and caudalis of Sp5. Labeled cells in DCN were either fusiform or multipolar cells, whereas those in Sp5 varied in size and shape. Injections of anterograde tracers into either CN or Sp5 resulted in terminal labeling in ICX primarily on the contralateral side. Most projection fibers from Sp5 terminated in a laminar pattern from ventromedial to dorsolateral within the ventrolateral ICX, the ventral border of IC, and the ventromedial edge of IC (collectively termed "the ventrolateral border region of IC," ICXV). Less dense anterograde labeling was observed in lateral and rostral ICX. Injecting different tracers into both Sp5 and CN confirmed the overlapping areas of convergent projections from Sp5 and CN in IC: The most intense dual labeling was seen in the ICXV, and less intense dual labeling was also observed in the rostral part of ICX. This convergence of projection fibers from $\mathrm{CN}$ and Sp5 provides an anatomical substrate for multimodal integration in the IC. J. Comp. Neurol. 495:100-112, 2006. ๑ 2006 Wiley-Liss, Inc.
\end{abstract}

Indexing terms: external cortex of inferior colliculus; somatosensory; multimodal integration; vocalization

The inferior colliculus (IC) contains three subdivisions: the central nucleus (CIC), surrounded by a dorsal cortex (DCIC) and a lateral external cortex (ICX) (Morest and Oliver, 1984; Faye-Lund and Osen, 1985). This overall organization, as well as the cellular anatomy of the IC follows a similar pattern across species, including avians, rodents, and primates (Osen, 1972; FitzPatrick, 1975; Knudsen, 1983; Morest and Oliver, 1984; Faye-Lund and Osen, 1985; Wagner et al., 2003). The CIC forms part of the "classical" auditory pathway that terminates in primary auditory cortex. It receives input from the majority of auditory ascending projections and displays sharply tuned, low-threshold neuronal properties (Aitkin et al., 1975; Cant, 1982; Oliver, 1987; Shneiderman and Henkel, 1987; Henkel and Brunso-Bechtold, 1993; Oliver et al., 1995; Schofield and Cant, 1996; Ota et al., 2004). The DCIC and ICX are the part of the "nonclassical" auditory pathway, receiving not only auditory inputs, but also nonauditory projections (primarily to the ICX), and descend- ing inputs from the auditory cortex (Aitkin et al., 1981; Willard and Martin, 1983; Coleman and Clerici, 1987; Kunzle, 1998; Ota et al., 2004).

Functional differences among subnuclei of the IC have been implied by the distinct physiological response properties of single neurons in each division. In contrast to the sharply tuned neuronal responses in CIC, neurons in the

Grant sponsor: National Institute on Deafness and Other Communication Disorders, National Institutes of Health; Grant number: R01 DC DC004825; Grant sponsor: Tinnitus Research Consortium; Grant number: P30 DC-05188.

*Correspondence to: Susan Shore, Kresge Hearing Research Institute, Department of Otolaryngology, University of Michigan, 1301 East Ann St. Ann Arbor, MI 48109-0506. E-mail: sushore@umich.edu

Received 10 May 2005; Revised 20 July 2005; Accepted 23 September 2005

DOI 10.1002/cne.20863

Published online in Wiley InterScience (www.interscience.wiley.com). 
ICX are broadly tuned to tonal stimuli, and respond more vigorously to spectrally complex stimuli such as vocalizations (Aitkin et al., 1975, 1978, 1981, 1994; Popelar and Syka, 1982; Syka et al., 2000; Suta et al., 2003; Ota et al., 2004). ICX neurons are further distinguished by their responsiveness to multimodal stimulation (Aitkin et al., 1978, 1981). Specifically, acoustically evoked neuronal activity of ICX neurons can be modulated by electrical stimulation of Sp5 (Jain and Shore, 2004; Shore, 2005b).

The connections and physiology of the ICX have suggested that one function of this region may be to integrate multiple sensory inputs. An anatomical basis is required to fully elucidate the extent of interaction of the auditory and somatosensory representations at the level of IC. However, such information is scarce in the literature. While there is evidence, using retrograde tracing techniques, that Sp5 projects to the IC (Aitkin et al., 1981; Coleman and Clerici, 1987), only one study, in the hedgehog, documented the terminal distribution of trigeminal endings in the IC (Kunzle, 1998). That study demonstrated that the terminal projections in the ICX were confined to a restricted band primarily in the ventrolateral IC. Direct projections from the cochlear nucleus (CN) to the IC have been reported across species (Osen, 1972; Ryugo et al., 1981; Cant, 1982; Coleman and Clerici, 1987; Oliver et al., 1997, 1999), but there is no anatomical evidence demonstrating a convergence of auditory and trigeminal pathways in the IC, the prerequisite for its participation in multimodal integration.

In the present study, we explored the dual projections from the $\mathrm{CN}$ and the Sp5 to the IC in the guinea pig, using both retrograde and anterograde tracing techniques.

\section{MATERIALS AND METHODS Animal preparation}

Young female guinea pigs ( $\mathrm{n}=17$; weight 250-350 g) were anesthetized with intramuscular injections of ketamine hydrochloride (Ketaset; $40 \mathrm{mg} / \mathrm{kg}$ ) and xylazine (Rompun; $10 \mathrm{mg} / \mathrm{kg}$ ) and placed in a stereotaxic frame (David Kopf, Tujunga, CA). Rectal temperature was monitored and maintained at $38 \pm 0.5^{\circ} \mathrm{C}$ with a thermostatically controlled heating pad. All procedures were performed in accordance with the NIH Guidelines for the Care and Use of Laboratory Animals (NIH Publication 80-23)
TABLE 1. Summary of Injection of Tracers in Different Experiment Groups

\begin{tabular}{|c|c|c|c|c|}
\hline \multirow[b]{2}{*}{ Subjects } & \multirow{2}{*}{$\begin{array}{l}\text { Experiment } \\
\text { group }\end{array}$} & \multicolumn{3}{|c|}{ Injection of tracers } \\
\hline & & IC & $\mathrm{CN}$ & Sp5 \\
\hline 041805 & $\mathrm{R}^{1}$ & FR & & \\
\hline 041504 & $\mathrm{R}$ & BDA & & \\
\hline 062404 & $\mathrm{R}$ & FR & & \\
\hline 062703 & $\mathrm{R}$ & FR & FG & \\
\hline 011404 & $\mathrm{R}$ & FR & & \\
\hline 101404 & $\mathrm{~A}^{2}$ & & BDA & \\
\hline 020905 & A & & BDA & \\
\hline 072303 & A & & BDA & \\
\hline 071603 & A & & FG & \\
\hline 091604 & A & & & BDA \\
\hline 010605 & A & & & BDA \\
\hline 122903 & A & & & BDA \\
\hline 110104 & A & & & BDA \\
\hline 081604 & A & & & FG \\
\hline 082604 & $\mathrm{~A}$ & & & FG \\
\hline 090904 & A, dual injections & & BDA & FR \\
\hline 112904 & A, dual injections & & FG & BDA \\
\hline
\end{tabular}

${ }^{1} \mathrm{R}$, retrograde tracing experiment.

${ }^{2} \mathrm{~A}$, anterograde tracing experiment.

and guidelines provided by the University of Michigan (UCUCA).

\section{Retrograde tracing experiments}

The present study employed three neural tracers (all diluted in phosphate-buffered saline (PBS), $\mathrm{pH}$ 7.4): biotinylated dextran-amine (BDA, MW 10,000, Molecular Probes, Eugene, OR), Fluoro-Ruby (FR, Molecular Probes), and FluoroGold (FG, Fluorochrome, Englewood, $\mathrm{CO})$. These tracers can label either anterograde or retrograde projections with high quality (Shore and Moore, 1998; Vercelli et al., 2000). Detailed information on injection of tracers is summarized in Table 1.

Retrograde tracers were injected into the ICX using stereotaxic coordinates $(2-3 \mathrm{~mm}$ lateral to lateral edge of middle line, $2-3 \mathrm{~mm}$ rostral to the anterior edge of the transverse sinus, and 4-6 mm ventral to the dural surface). Either 5\% FR $(\mathrm{n}=4)$ or $10 \% \operatorname{BDA}(\mathrm{n}=1)$ was injected into IC using a Hamilton microsyringe equipped with a glass micropipette $(20-30 \mu \mathrm{m}$ tip). One animal (subject 062703) received multiple injections of FR in the left IC (CIC and ICX) and injection of FG in the left CN.

Five to eight days after the injections, animals were euthanized with Nembutal (15 mg/kg, i.p.) and transcardially perfused with $100 \mathrm{ml}$ of $0.1 \mathrm{M} \mathrm{PBS}$, followed by 400

$\begin{array}{ll}7 & \text { Facial nucleus } \\ \text { AVCN } & \text { anteroventral cochlear nucleus } \\ \text { BDA } & \text { biotinylated dextran-amine } \\ \text { CIC } & \text { central nucleus of inferior colliculus } \\ \text { CN } & \text { cochlear nucleus } \\ \text { Cu } & \text { cuneate nucleus } \\ \text { DAB } & 3,3^{\prime} \text {-diaminobenzidine tetrahydrochloride } \\ \text { DCIC } & \text { dorsal cortex of inferior colliculus } \\ \text { DCN } & \text { dorsal cochlear nucleus } \\ \text { FG } & \text { fluorogold } \\ \text { FR } & \text { fluoro-ruby } \\ \text { Gr } & \text { gracile nucleus } \\ \text { IC } & \text { inferior colliculus } \\ \text { icp } & \text { inferior cerebellar peduncle } \\ \text { ICX } & \text { external cortex of inferior colliculus } \\ \text { ICXV } & \text { ventrolateral border region of IC } \\ \text { IO } & \text { inferior olive }\end{array}$

$\begin{array}{ll}\text { LL } & \text { lateral lemniscus } \\ \text { ml } & \text { medial lemniscus } \\ \text { mcp } & \text { middle cerebellar peduncle } \\ \text { PBS } & \text { phosphate-buffered saline } \\ \text { Pn } & \text { Pontine reticular nucleus } \\ \text { PVCN } & \text { posteroventral cochlear nucleus } \\ \text { s5 } & \text { Sensory root of trigeminal nerve } \\ \text { scp } & \text { superior cerebellar peduncle } \\ \text { SG } & \text { Subnucleus Gelatinosus } \\ \text { sp5 } & \text { spinal trigeminal tract } \\ \text { Sp5 } & \text { spinal trigeminal nucleus } \\ \text { Sp5C } & \text { pars caudalis of spinal trigeminal nucleus } \\ \text { Sp5I } & \text { pars interpolaris of spinal trigeminal nucleus } \\ \text { Sp5O } & \text { pars oralis of spinal trigeminal nucleus } \\ \text { tz } & \text { trapezoid body } \\ \text { VCN } & \text { ventral cochlear nucleus }\end{array}$


$\mathrm{ml}$ of $4 \%$ paraformaldehyde in PBS. Following perfusionfixation, the brain was isolated and placed in the same fixative for 2 hours at $4^{\circ} \mathrm{C}$. The brain was transferred into $30 \%$ sucrose in $0.1 \mathrm{M}$ PBS overnight at $4^{\circ} \mathrm{C}$. The brainstem and midbrain were then sectioned on a freezing microtome at a thickness of $40-60 \mu \mathrm{m}$. The serial sections obtained from each animal were divided into two groups, each consisting of a series of alternate serial sections. Sections were mounted in serial order on clean glass slides and air dried.

For FR injections, the first series of the alternate serial sections was dehydrated and coverslipped with Microcover (Micron, Fairfax, VA) and examined under a fluorescent microscope equipped with a digital camera (Leica DML, Leica Microsystems Wetzlar, Germany). The second series of alternate sections was counterstained with neutral red to reconstruct the labeled cells within the brainstem. For visualization of BDA, the following protocol was followed: sections were first incubated for 2 hours in Avidin $\mathrm{DH}$ : biotinylated horseradish peroxidase $\mathrm{H}$ complex (Vectastain Elite ABC kit, Vector Laboratories, Burlingame, CA), in 0.1 M PBS with 0.1\% Triton X-100 (Sigma, St. Louis, MO; 9002-93-1), pH 7.4, then reacted with $3,3^{1}$ diaminobenzidine tetrahydrochloride (DAB, Vector Laboratories). Slides were counterstained with neutral red, dehydrated, coverslipped, and examined using a lightfield microscope (Leica DML).

The injection site in the IC was defined as a central, bright core and a less bright, surrounding halo (Vercelli et al., 2000). To reconstruct the injection site in IC, photomicrographs of the counterstained section (or adjacent counterstained section for FR injections) were digitized and imported into Freehand (Macromedia, San Francisco, CA). The IC was drawn on the photomicrograph using a freehand drawing pencil. The photomicrograph of the injection site was digitized, imported to Freehand, and overlapped onto the IC drawing. Finally, the injection area was outlined and merged onto the layer containing the drawing of IC.

Nuclear and subnuclear boundaries in the trigeminal nucleus were determined using the following criteria: The level of the rostral pole of the facial motor nucleus typically corresponds to the boundary between the principle nucleus and the spinal trigeminal nucleus (Sp5); The rostral border of pars interpolaris of Sp5 (Sp5I) generally follows the rostral end of the inferior olivary complex, and its caudal border can be determined by the point where the "displaced" substantia gelatinosa becomes contiguous with the spinal tract (Jacquin et al., 1986, 1993; Shigenaga et al., 1986). The templates were drawn from the counterstained slides roughly at $1,000-\mu \mathrm{m}$ intervals extending from the oral region to the caudal region of Sp5. Cells with homogeneous labeling of the cytoplasm, a relatively clear central nuclear zone, and at least one labeled dendrite were identified as retrogradely labeled neurons. Labeled neurons in the trigeminal nuclei were visualized using either light or fluorescent microscopy and mapped onto the templates. Photomicrographs of retrogradely labeled neurons were digitized and imported to Adobe PhotoShop (San Jose, CA) for labeling and contrast adjustment. Cell counting was conducted on both sides of the brainstem except in one animal (062703) that received multiple injections in both left IC and left CN with different tracers. In this animal cell counting was omitted in the ipsilateral CN. Cell counts in both Sp5 and CN were obtained from the first series of the alternate sections, the number of cell counts was multiplied by 2 to achieve the total cell counts, and the data were corrected for double counting errors using Abercrombie's correction (Corrected number $=$ count $\times($ section thickness $) /($ section thickness + cell height) (Abercrombie, 1946).

\section{Anterograde tracing experiments}

Injections in Sp5. The surgical procedure for injection of anterograde tracers into the Sp5 has been described previously (Zhou and Shore, 2004). Briefly, the injection pipette was positioned into the Sp5 using stereotaxic coordinates ( $3 \mathrm{~mm}$ lateral to the midline, $2 \mathrm{~mm}$ caudal to the posterior edge of transverse sinus, and $10.4 \mathrm{~mm}$ ventral to the surface of the dura). One of two tracers (10\% BDA, $\mathrm{n}=$ 4 or $2 \% \mathrm{FG}, \mathrm{n}=2$ ) was pressure-injected into Sp5 using a Hamilton syringe to a total volume of $0.1-0.3 \mathrm{~L}$. A portion of the data, demonstrating the anterograde projection to $\mathrm{CN}$ in one animal, has been published previously (Zhou and Shore, 2004). After removing the pipette the skin was sutured and the animals were allowed to recover. Five to six days later the animals were euthanized and transcardially perfused with PBS, followed by $4 \%$ paraformaldehyde in PBS. The brain was removed from the skull, postfixed for 2-4 hours, and cryoprotected in 30\% sucrose overnight. The brainstem and midbrain were then sectioned on a freezing microtome at a thickness of 40-60 $\mu \mathrm{m}$. Alternate slides were mounted in serial order on clean glass slides and air dried.

Injections in $\boldsymbol{C N}$. Injections into the left $\mathrm{CN}$ were made to document the terminal distributions of the $\mathrm{CN}$ projection to IC in the guinea pig $(n=4)$. Multiple injections were made along the injection track from the surface of DCN down to the lateral PVCN. Special care was taken to deposit tracers laterally in the $\mathrm{CN}$ to avoid the spread of injections to adjacent structures, e.g., the inferior cerebellar peduncle (icp). Sometimes multiple injections resulted in large injection sites, which could fill the whole CN. Detailed microscopic analysis of these large injections indicated that the injection site indeed was restricted to the $\mathrm{CN}$ and the icp was not contaminated. Labeled axons of the dorsal/intermediate acoustic striae and the trapezoid body emerged from the injection sites in the DCN and VCN.

Dual injections in both Sp5 and $\boldsymbol{C N}$. In addition to individual injections in the $\mathrm{CN}$, dual injections with different tracers were made into both $\mathrm{CN}$ and $\mathrm{Sp} 5(\mathrm{n}=2)$ using the protocol described above.

Tissue processing and reconstruction. Tissue processing and reconstruction of injection sites and anterograde projections generally followed the same procedure as in the retrograde tracing experiments. Photomicrographs of puncta were digitized and imported to either Adobe PhotoShop for contrast adjustment or Freehand for the purpose of reconstruction. Anterograde terminal endings in the IC were drawn onto individual transverse sections of the IC. Each dot represents 1-3 terminal endings. In the study of dual injections in both Sp5 and $\mathrm{CN}$, fluorescent dye (Alexa-488 conjugated with streptavidin in $0.1 \mathrm{M}$ PBS with $0.3 \%$ Triton $\mathrm{X}-100$, Molecular Probes) was used to visualize the BDA product for the purpose of double labeling. Sections were first rehydrated in $0.1 \mathrm{M}$ PBS for 10 minutes, followed by incubation for 2 hours with Alexa-488 conjugated streptavidin (1:200). After thoroughly washing in $0.1 \mathrm{M}$ 
Fig. 1. Retrograde labeling in the Sp5 and the CN after an injection of FR into the IC in one animal (subject 011404). The shaded area in $(\mathbf{A})$ represents the injection site in the IC. B-D: drawings of 40- $\mu \mathrm{m}$ transverse sections across the contralateral CN. Each dot represents a labeled neuron. E-I: drawings of rostral to caudal, 1-mm transverse sections across the medulla. The retrogradely labeled neurons are located mainly on the contralateral side of Sp5, mostly in the pars interpolaris (Sp5I) and pars caudalis (Sp5C). Scale bars $=1 \mathrm{~mm}$ in D (applies to $\mathrm{B}-\mathrm{D}) ; 3 \mathrm{~mm}$ in I (applies to E-I).
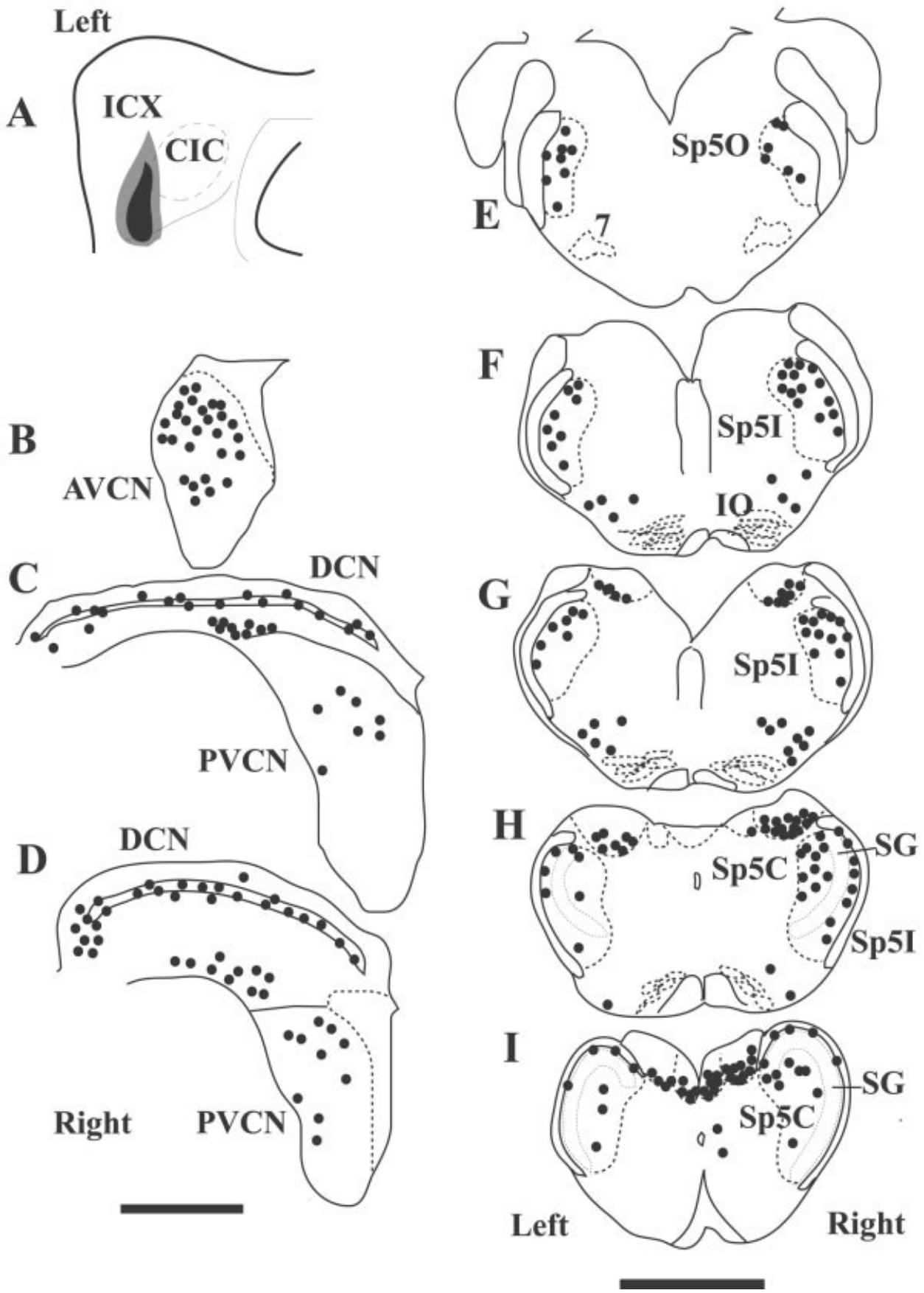

PBS, sections were dehydrated, cleared, and coverslipped using the methods described above. To obtain clear images of the terminal endings, serial photomicrographs were imported to Metamorph (Universal Imaging, Downingtown, PA) to generate a Z-projection of stacks.

Definition of IC subdivisions. The subdivisions of IC were based primarily on cytoarchitectural and topographical criteria (Morest and Oliver, 1984; Faye-Lund and Osen, 1985; Saldana and Merchan, 1992; Oliver, 2005). The CIC was identified by the centrally localized nucleus containing disc-shaped neurons oriented in parallel arrays. The DCIC, containing predominantly stellate neurons without obvious orientation, covered the dorsal surface of CIC. The ICX, containing a mixture of large and small stellate cells, was localized lateral, ventrolateral, and rostral to the CIC. We adopted the proposed subdivisions and terminology of the ICX but with some modifications (Oliver et al., 1999; Oliver, 2005). Specifically, the ICX was subdivided into three regions: a) the ventral border region of IC (ICXV), b) the lateral ICX, and c) the rostral ICX. 


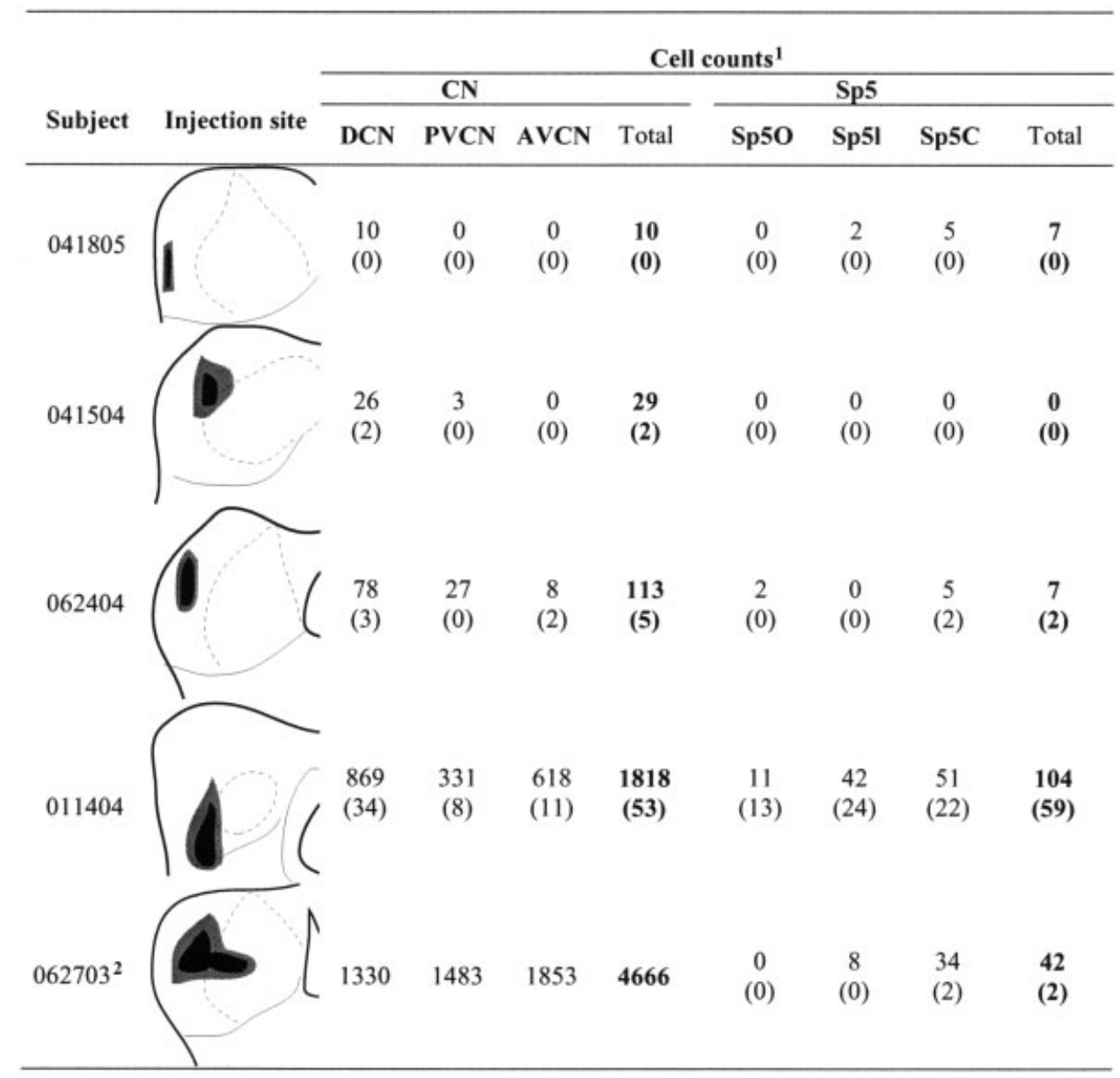

Fig. 2. Retrogradely labeled cell counts in the $\mathrm{CN}$ and Sp5 after injection of retrograde tracing tracers in the IC. ${ }^{1}$ The number in parenthesis below represents the cell counts on the ipsilateral side; ${ }^{2}$ ipsilateral $\mathrm{CN}$ cell counting was not conducted in this animal.

a) The ICXV includes the ventrolateral nucleus (corresponding to layer 3 of the ICX; Oliver, 2005), the border area below the IC, and the ventromedial edge of CIC (also called the pericentral area; Kunzle, 1993). No clear morphological boundary was observed between the ventrolateral nucleus and the border area, and neurons in each area had a similar morphology, i.e., they contained mainly large and small stellate cells. The pericentral area was incorporated into the ICXV because, like the other two divisions, it receives somatosensory input (Kunzle, 1993).

b) The lateral ICX includes the fibrous layer 1 and the small cellular layer 2 with low neuronal density.

c) We did not differentiate the structures rostral to the CIC, but referred to them as "rostral ICX" (see Discussion), which contains sparsely packed cells.

\section{RESULTS \\ Retrograde tracing experiment}

Labeled cells in Sp5. Following tracer injections in the IC, retrogradely labeled cells were distributed longitudinally along the rostral-caudal length of the spinal trigeminal nuclei, with more labeling on the contralateral side. The most dense concentrations of labeled cells were in the pars interpolaris (Sp5I) and pars caudalis (Sp5C,
Fig. 1E-I, 2). There was a tendency for the retrogradely labeled neurons to be distributed preferentially along the lateral (i.e., marginal) and/or dorsal region of Sp5I. However, cell-labeling in the regions of the ventral and/or medial region was also evident. The labeled cells in Sp5C were found primarily in the deep layer (subnucleus magnocellularis) and marginal layer (subnucleus marginalis), with few in the layer of subnucleus gelationsus (Fig. $1 \mathrm{H}-$ I). The projection neurons in Sp5 had either polygonal somata, ranging in diameter from $12 \times 14 \mu \mathrm{m}$ to $24 \times 32$ $\mu \mathrm{m}$, which were found in the medial region of Sp5 (Fig. $3 \mathrm{~A}$ ), or elongated somata, ranging from $19 \times 30 \mu \mathrm{m}$ to $13 \times 48 \mu \mathrm{m}$, which usually were found in the marginal region of Sp5I and Sp5C (Fig. 3B). In addition, retrogradely labeled cells were found in other areas within the medulla, including the reticular formation and dorsal column nuclei (Fig. 1).

Labeled cells in $\boldsymbol{C N}$. Following tracer injections in the IC, projection neurons were found in both the dorsal and ventral divisions of $\mathrm{CN}$ (DCN and VCN), with more labeling on the contralateral side (Fig. 1B-D, 2). When injections were restricted to the ICX, all or most of the labeled cells were found in DCN and few were in the PVCN (Table 2 ; subjects 041805,041504 , and 062404). The projection cells in DCN were either fusiform cells (located in the 

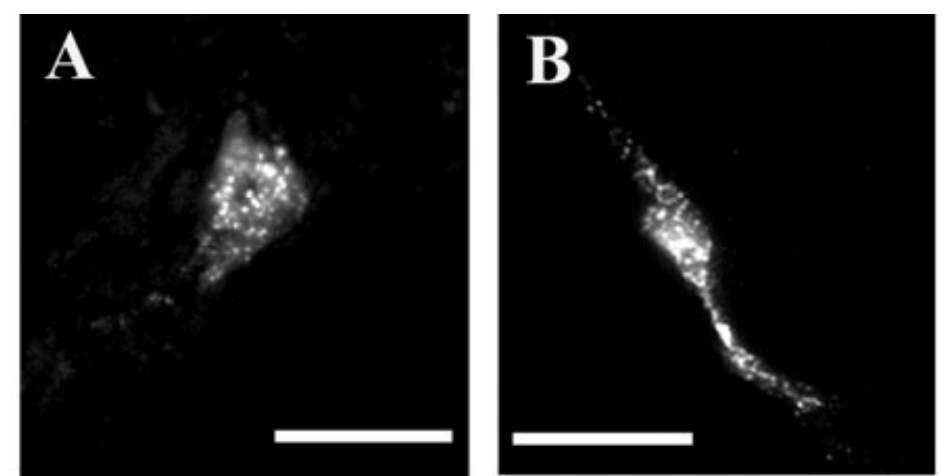

Fig. 3. Photomicrographs of labeled neurons in both the Sp5 and the CN following injections of FR into the ICX. The projection neurons in Sp5 had either polygonal somata (A, medial region of Sp5I), or elongated somata (B, marginal region of Sp5I). Labeled neurons in $\mathrm{CN}$ are fusiform cells in layer II of DCN (C) multipolar cell and small, elongated cell in deep DCN $(\mathbf{D})$, and small round cell in $\operatorname{PVCN}(\mathbf{E})$. Scale bars $=25 \mu \mathrm{m}$.
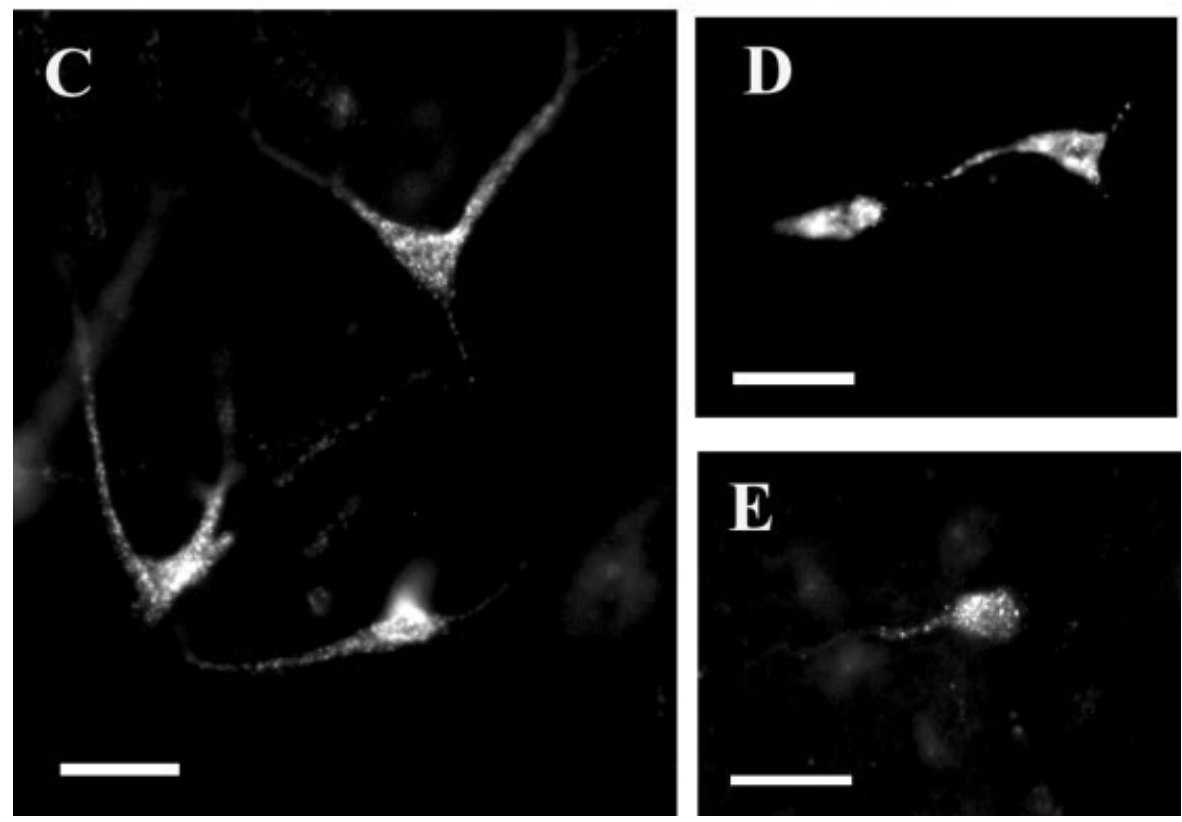

fusiform cell layer, $8 \times 40 \mu \mathrm{m}$ to $20 \times 32 \mu \mathrm{m}$, Fig. $3 \mathrm{C}$ ), multipolar cells or small elongated cells (located mainly in deep layer, $12 \times 20 \mu \mathrm{m}$ to $24 \times 40 \mu \mathrm{m}$, Fig. 3D). Retrogradely labeled cells in VCN were multipolar or round and were located mainly in the medial and dorsolateral regions of PVCN $(10 \times 16$ to $14 \times 32 \mu \mathrm{m}$, Fig. $3 \mathrm{E})$, as well as $\operatorname{AVCN}(11 \times 14 \mu \mathrm{m}$ to $16 \times 20 \mu \mathrm{m})$.

\section{Anterograde experiments}

Injections into Sp5. Data analysis was based on two animals in which the injections were limited to the Sp5 without diffusion to the adjacent areas and four animals where the injection sites displayed some diffusion to the inferior cerebellar peduncle (icp). In the two animals that received restricted injections in the Sp5 the injections were primarily centered in the Sp5I, with little spread to the Sp5C. In the other four animals the injection sites were located in either $\operatorname{Sp5I}(n=2)$ or $\operatorname{Sp5I/Sp5C}(n=2)$. The distribution pattern of anterograde projections to the IC observed in all of these experiments was identical, indicating that 1 ) the icp does not participate in this projection, and 2) the projection pathway from the Sp5C to the IC is similar to that from the Sp5I to the IC. Furthermore, the number of labeled terminal endings in the ICX was closely related to the amount of tracer deposited in the Sp5, but not with that of tracer that diffused into the icp. No labeled terminals were seen in the ICs of the animals with restricted icp injections, and there were no labeled cells in icp after IC retrograde injections. Thus, we are confident that there was no contamination uptake of injected tracer from "fibers of passage" and that the anterograde projection to ICX observed in the present study originated in the trigeminal nuclei. In addition, small injections around the medial border of $\operatorname{Sp5I}(\mathrm{n}=1)$ or ventral area of the caudal part of $\operatorname{Sp} 5 \mathrm{C}(\mathrm{n}=3)$ did not result in anterograde labeling in IC (data not shown).

Anterograde projections from Sp5 to IC were more prevalent on the contralateral side (Fig. 4). Most labeled fibers crossed the midline, ascended with the lateral lemniscus, and entered the IC ventrally (Fig. 4A-D). Some labeled Sp5 fibers did not cross the midline and directly ascended to the ipsilateral IC. Within the IC, most labeled fibers continued laterally and dorsally to the lateral ICX and gave rise to puncta or terminal endings (Fig. 4E-I,J-N). Some fibers ran medially along the ventral edge of CIC and formed terminal endings. The majority of the Sp5 terminations were in the ICXV (see Materials and Methods for IC classification) and were distributed nonhomogenously along a ventromedial to dorsolateral axis (Fig. 
$4 \mathrm{~F}, \mathrm{G}, \mathrm{K})$. Some labeled terminal endings were also found at the rostral end of ICX (Fig. 4E,J).

Labeled fibers in the IC were of small to medium thickness $(0.6-1.8 \mu \mathrm{m})$ (Fig. 5A,B), and labeled terminal endings were en passant or small terminal boutons $(0.8-4$ $\mu \mathrm{m})$ (Fig. 5B-D). The labeled terminals appeared to make contact with either small cells $(\sim 4 \mu \mathrm{m}$ in diameter, Fig. $5 \mathrm{C})$ or large multipolar or round cells $(\sim 14 \mu \mathrm{m}$ in diameter, Fig. 5D).

Injections into $\boldsymbol{C N}$. Injections of tracers into the $\mathrm{CN}$ resulted in anterograde labeling of projection fibers to the IC, with more labeling on the contralateral side (Fig. 6). The labeled fibers converged with either the trapezoid body or dorsal/intermediate acoustic striae, ascended primarily in the contralateral lateral lemniscus, and entered in the IC.

Following multiple injections in the DCN and VCN, in most cases labeled CN terminal endings were found in both the CIC and ICX (including ICXV, Figs. 6-8). In one animal, in which the injections were restricted to the ventrolateral DCN and lateral PVCN, most of the labeled terminals were found in the contralateral IC primarily in the ICXV, lateral CIC, lateral and rostral ICX (Fig. 6). Labeled CN terminal endings of projection fibers from the CN to the ICXV were either of "en passant" type or small terminal boutons. No morphological differences were observed between the terminal endings in ICX and lateral CIC. A similar, but less intense, distribution pattern was observed in the ipsilateral IC. Little anterograde labeling was found in the DCIC.

Convergence of Sp5 and CN projections. The major area of convergence of terminals from Sp5 and CN was the ICXV. Labeled terminal endings of projection fibers from the $\mathrm{CN}$ to this region were either of en passant type or small terminal boutons (0.8-3.2 $\mu \mathrm{m}$ in diameter, Fig. 6B). Overlap of the Sp5 and CN terminations was determined by superimposing drawings of Sp5 anterograde projections in IC with drawings of $\mathrm{CN}$ anterograde projections in IC (Fig. 7). Most of the convergence from the two systems occurred in the ICXV (Fig. 7C,D, triangles). Some convergence was found in the lateral ICX (Fig. 7C,D) and rostral ICX (Fig. 7A,B).

\section{Dual injections in both $\mathrm{CN}$ and Sp5}

Five animals received dual injections of anterograde tracers in both CN and Sp5. In two of these animals the injection sites were restricted to the $\mathrm{CN}$ and the Sp5. These data are presented below. In the other three animals some spread to adjacent structures was evident. The data are not presented here other than to state that the results from these animals were generally consistent with those having restricted injections. The distribution of anterograde projections from the animals with $\mathrm{CN}$ and Sp5 injections was consistent with the corresponding distributions from animals with individual injections in either $\mathrm{CN}$ or Sp5.

Terminal distributions from the CN and Sp5 showed strong convergence in the ICXV (Fig. 8, filled triangle), and weaker convergence in the rostral ICX. In the ICXV where concentrated puncta from Sp5 were found, there were also numerous labeled terminal endings from the CN (Figs. 8, 9). The aggregated terminal endings of projection fibers from CN and Sp5 had similar morphological appearances. Both had small to medium-size
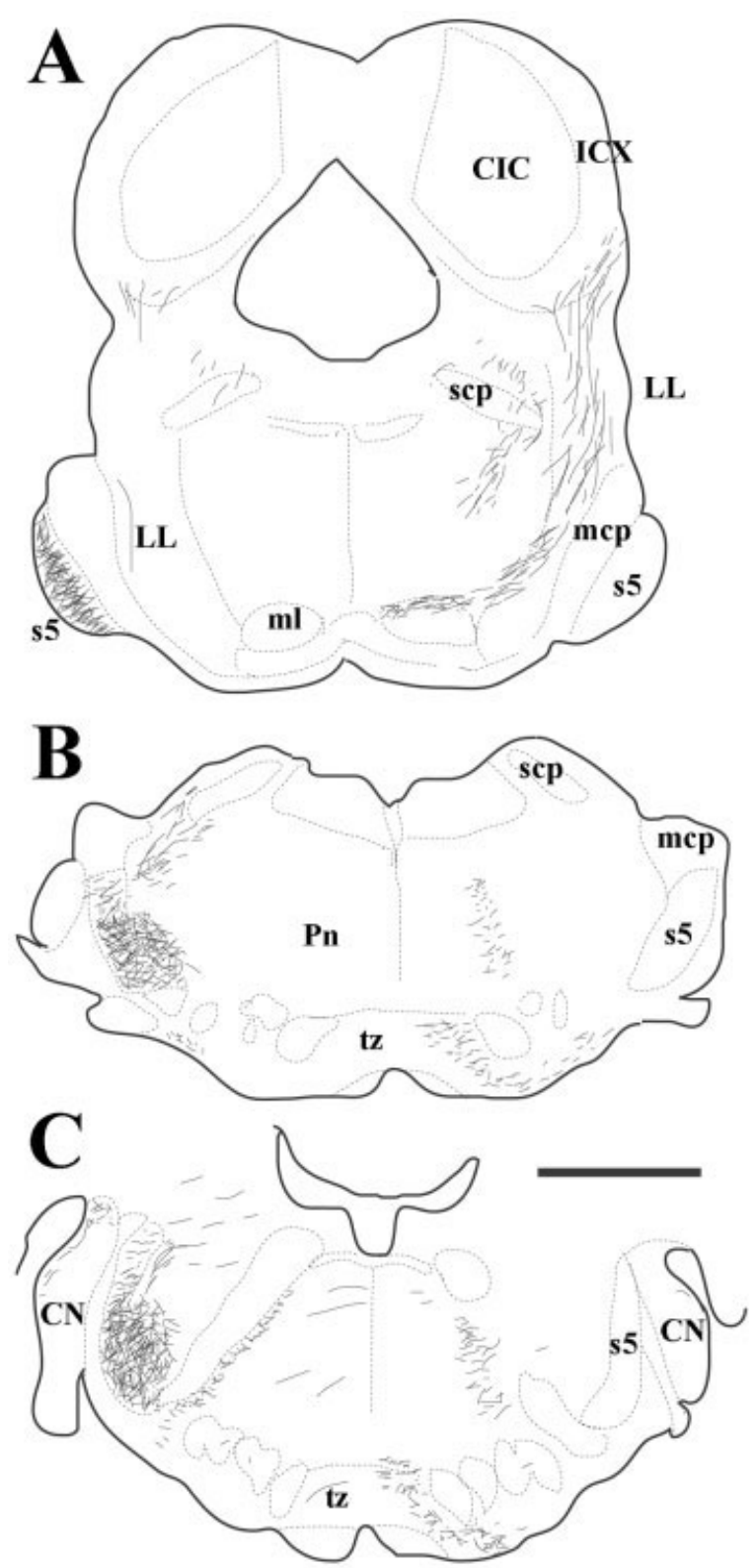

D

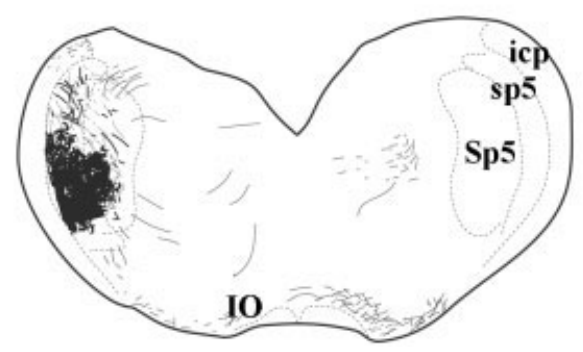

Figure 4 (Continued)

fibers $(0.5-2 \mu \mathrm{m})$, with terminal endings of either en passant or small terminal bouton types, with a size of 1-3 $\mu \mathrm{m}$ (Fig. 9). 
Fig. 4. Anterograde labeling in the IC after injections in the Sp5. A-D: Drawings of the labeled fibers in the brainstem following an injection of BDA in the Sp5 (122903). Most labeled fibers crossed the midline, ascended with the lateral lemniscus, and entered the IC ventrally. D: The injection site in the Sp5I. E-I,J-N: Reconstruction of the labeled terminal endings in the IC following injections in the $\mathrm{Sp} 5$ from two animals (E-I: 122903 and J-N: 110104). Each column shows drawings of $40-\mu \mathrm{m}$ transverse sections from the rostral to caudal ends of IC. The terminal endings are predominantly located in the contralateral ICXV (shaded area), in restricted lamina extending from ventromedial to dorsolateral (arrowed lines, $\mathrm{F}$ and $\mathrm{K}$ ). The density of the labeled terminal endings was not homogeneous along the ventrolateral lamina (arrowheads, G) Photomicrographs of the Sp5 injection site are displayed at the bottom of each column (I and N, respectively; Each dot represents 1-3 terminal endings. Scale bars $=2$ $\mathrm{mm}$ in drawings; $500 \mu \mathrm{m}$ in photomicrographs.
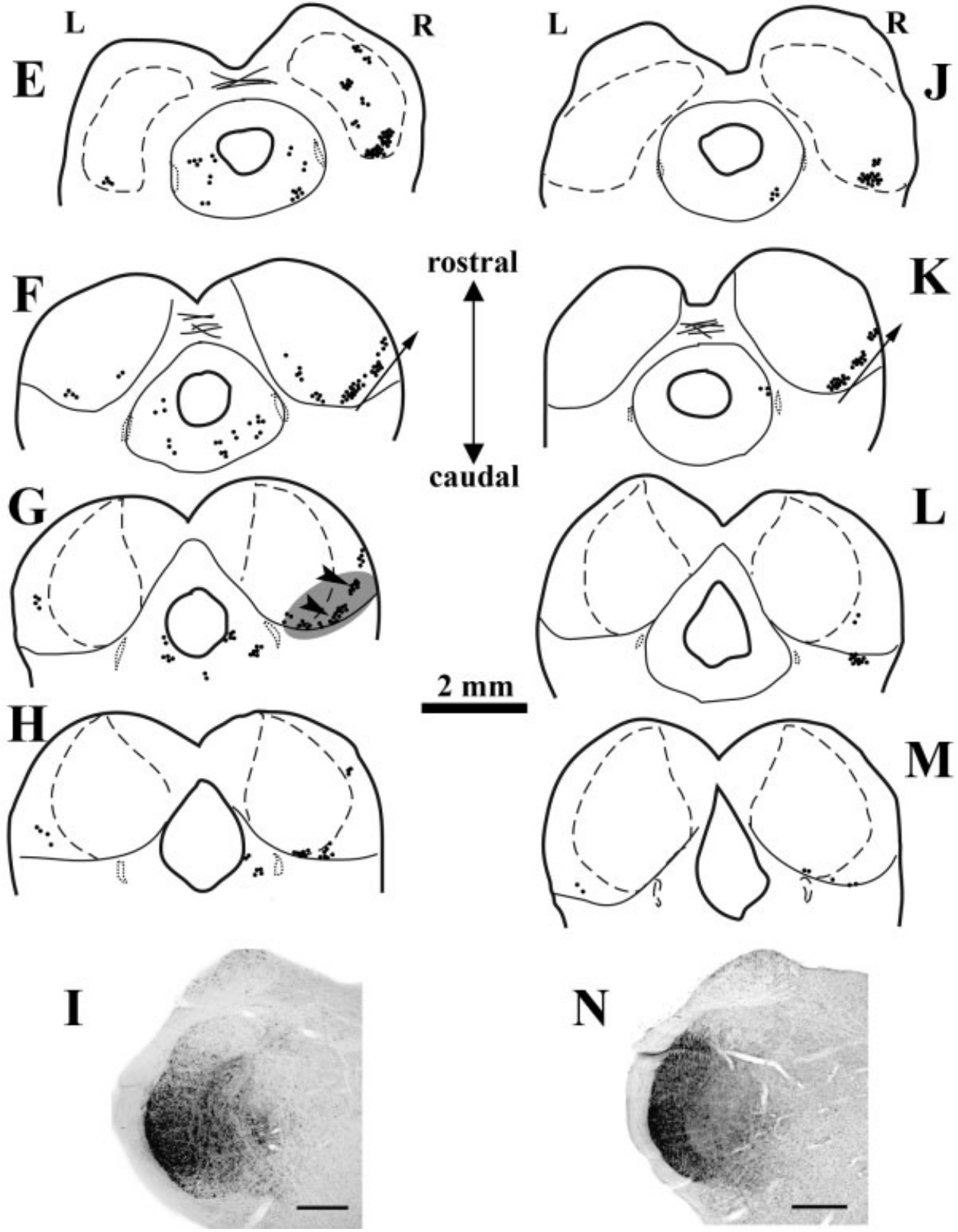

\section{DISCUSSION}

This is the first study to delineate the convergence of projections from Sp5 and CN in the IC. Neurons originating in Sp5C and Sp5I projected to IC in a restricted laminar pattern, terminating in the ICXV, lateral and rostral ICX. Neurons originating in $\mathrm{CN}$ also terminated in these regions. The most dense overlap of $\mathrm{Sp} 5$ and $\mathrm{CN}$ projections occurred in the ICXV.

In addition to morphological differences between the ICXV and lateral ICX, there was a major difference between the sources of their auditory inputs. The ICXV receives ascending auditory projections from $\mathrm{CN}$ or superior olive complex (Oliver et al., 1999; Loftus et al., 2004; Oliver, 2005), whereas the lateral ICX receives auditory inputs primarily from the CIC (Morest and Oliver, 1984;
Saldana and Merchan, 1992). The ICXV is also a region shown to drive the olivo-cochlear system (Groff and Liberman, 2003), and is dominated by units that respond selectively to certain directions or rates of frequency modulation (FM) in bats (Gordon and O'Neill, 1998; Gordon and O'Neill, 2000). Structures rostral to the CIC include several subdivisions (Morest and Oliver, 1984), but are poorly understood. Since many of them receive somatosensory projections (Wiberg et al., 1987; Paloff and Usunoff, 1992; Kunzle, 1993), we referred to these rostral structures simply as "rostral ICX."

\section{Projections from Sp5 to ICX}

Consistent with previous studies in other species (Aitkin et al., 1981; Coleman and Clerici, 1987; Li and Mizuno, 


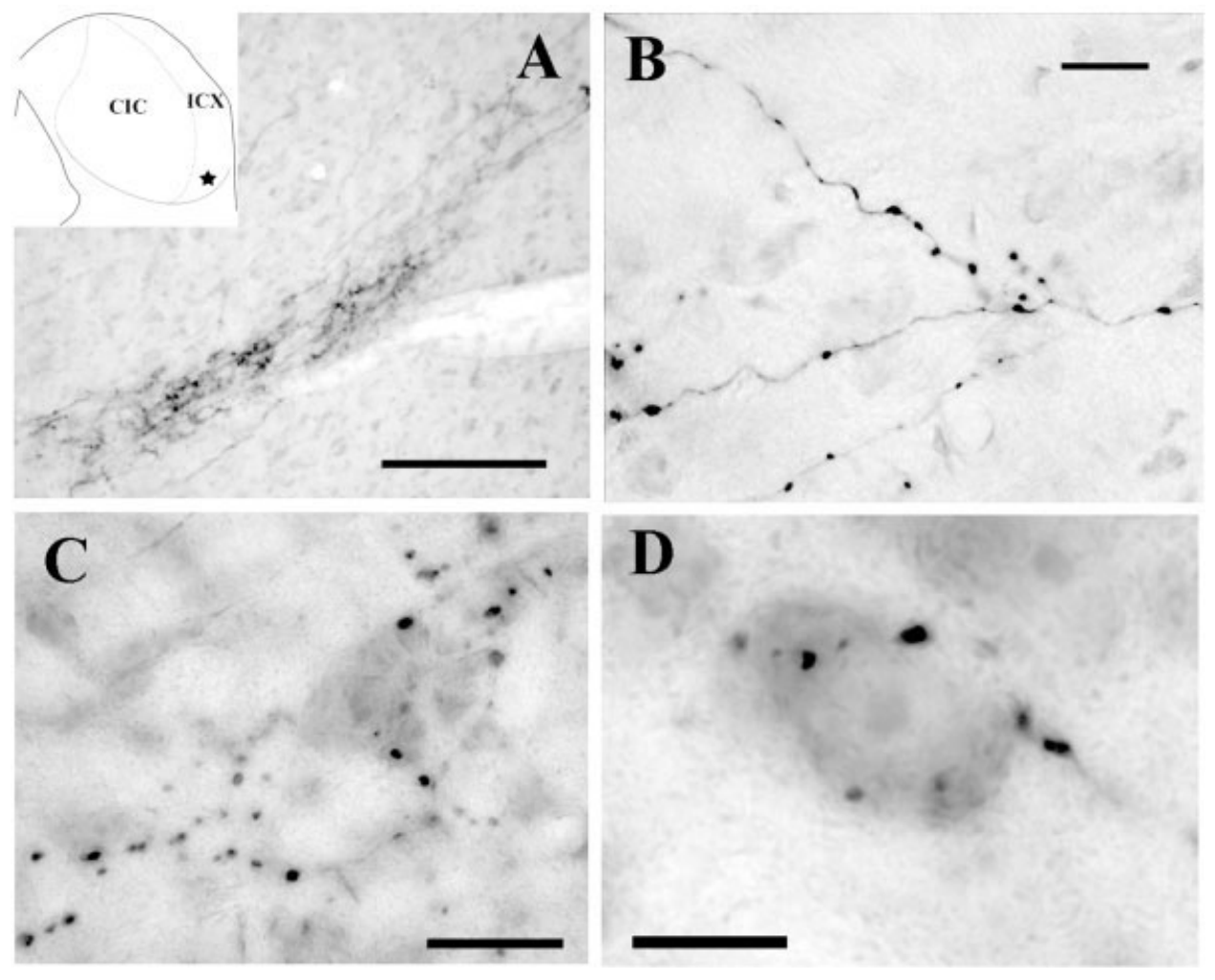

Fig. 5. Photomicrographs of labeled fibers and puncta in the ICX following injections in the Sp5. A,B: Photomicrographs of labeled fibers and terminal endings in the ICXV (A: $\times 10$ and B: $\times 40$ ). The star in the inset drawing of (A) indicates the locations of photomicrographs. Terminal labeling was in the form of en passant or terminal boutons. C,D: Photomicrographs of labeled terminals with higher magnification $(\times 100)$, small cell and large multipolar $(\mathrm{C})$ or round cell (D). Scale bars $=100 \mu \mathrm{m}$ in A; 10 $\mu \mathrm{m}$ in $\mathrm{B}, \mathrm{D} ; 20 \mu \mathrm{m}$ in $\mathrm{C}$.
1997; Kunzle, 1998), injections of retrograde tracers into the IC resulted in labeled cells in several areas throughout the medulla, including the Sp5, dorsal column nuclei, and reticular formation.

Retrogradely labeled cells in the Sp5I varied in size and shape, with a tendency to be aggregated in the dorsomedial and marginal areas, consistent with previous descriptions of this nonlaminated structure (Darian-Smith, 1973; Usunoff et al., 1997). The Sp5C, in contrast, is a laminated structure: 1) the outermost subnucleus marginalis, 2) the intermediate subnucleus gelatinosus, and 3) the medial subnucleus magnocellularis (Darian-Smith, 1973). The majority of retrogradely labeled cells in the $\mathrm{Sp} 5 \mathrm{C}$ in the present study were located in either the subnucleus marginalis or the subnucleus magnocellularis, whereas only a few were in the subnucleus gelatinosus. The paucity of labeled cells in the subnucleus gelatinosus indicates that the small gelatinosa cells do not project to the IC, consistent with the view that the majority of gelatinosa cells project within the trigeminal system, terminating on other cells in the Sp5C, and cells in the rostral structures, including Sp5I, Sp5O, and the main sensory nucleus (Darian-Smith, 1973).

The variation in size and shape of the labeled neurons in Sp5 might reflect the functional and morphological complexity of Sp5. In addition to their involvement in the modulation of pain (Hayashi et al., 1984; Usunoff et al., 1997), all three subdivisions of the Sp5 receive lowthreshold non-nociceptive afferents from head and face, such as those sensitive to gentle pressure and vibrissa deflection (Hayashi et al., 1984; Jacquin et al., 1986, 1988, 1993). The dorsomedial and marginal areas of the Sp5I and the deep and marginal layers of Sp5C were the predominant locations of retrogradely labeled cells in this study. These regions receive inputs from vocal tract/intra oral structures including the temporomandibular joint and tongue muscles, etc. (Romfh et al., 1979; Jacquin et al., 1986, 1988; Capra, 1987; Nazruddin et al., 1989; Takemura et al., 1991; Suemune et al., 1992).

The Sp5 terminal endings in the ICX formed a laminar pattern from ventromedial to dorsolateral that is consistent with that observed in an earlier tract-tracing study in the hedgehog (Kunzle, 1998). The terminal endings in the ICX differed from those seen in CN (Zhou and Shore, 2004). The labeled terminal endings in $\mathrm{CN}$ were of three major types: large irregular swellings (or mossy fiber), en passant/small terminal boutons, and terminal clusters, whereas only terminal bouton/en passant endings were observed in ICX. It is possible that the mossy fiber endings observed in the $\mathrm{CN}$ originate from a different group of neurons in Sp5.

The laminar pattern of the Sp5 projection to the IC is similar to that arising in the dorsal column nuclei and the spinal cord (Paloff and Usunoff, 1992; Kunzle, 1993). Also consistent with projections to the pericentral region from dorsal column nuclei (Kunzle, 1993), the present study showed Sp5 projections to the ventromedial edge of the IC, which forms part of the pericentral region.

\section{Projections from CN to ICX}

Both the retrograde and anterograde tract-tracing experiments support the notion that the major $\mathrm{CN}$ inputs to the ICX originate in the DCN (Aitkin et al., 1981; Ryugo et al., 1981; Oliver, 1984; Coleman and Clerici, 1987). Following multiple injections in the DCN and VCN, terminal 

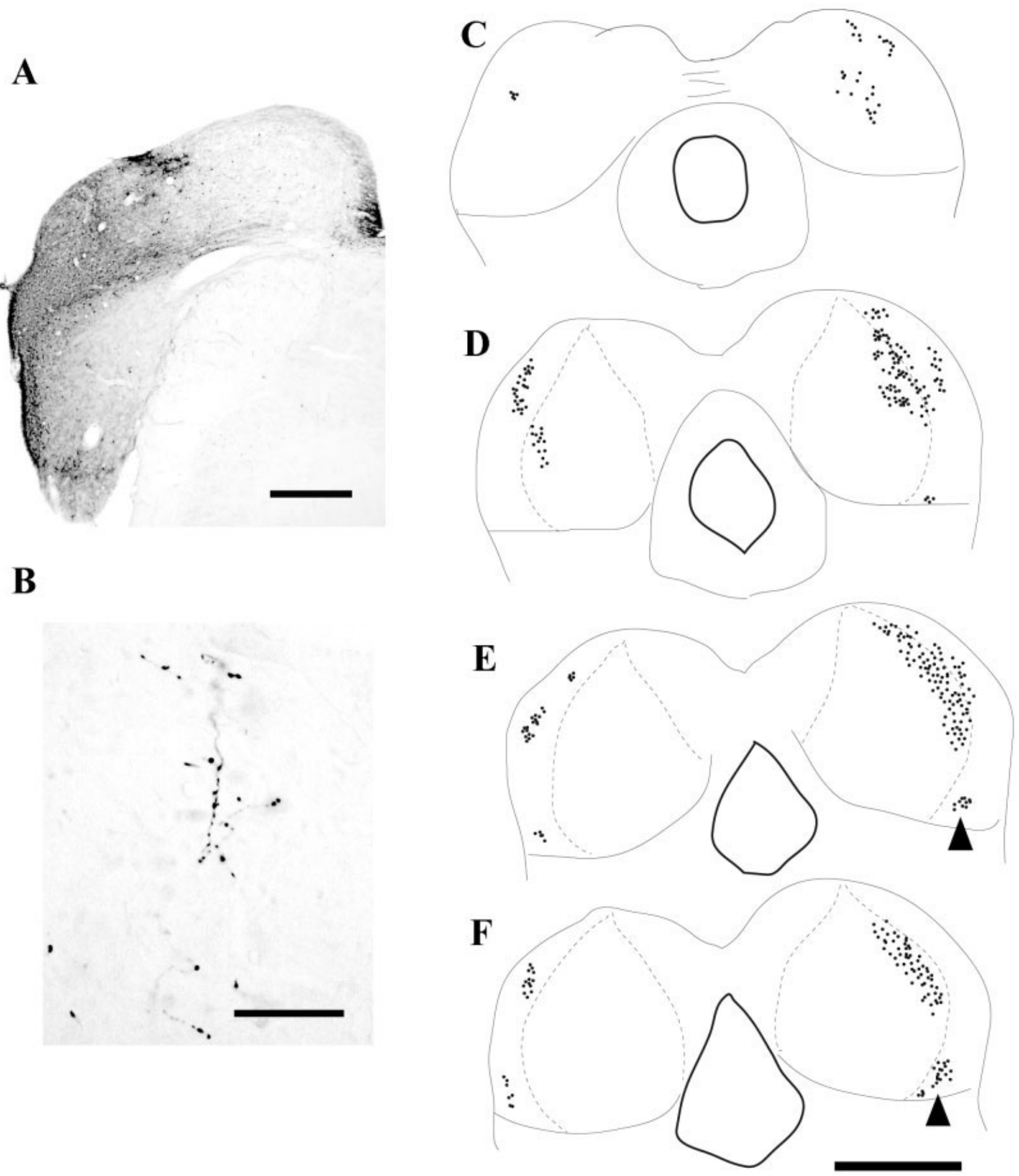

Fig. 6. Photomicrographs and drawings of anterograde terminal labeling in the IC following an injection of BDA in the CN (subject 101404). A: Injection site in the $\mathrm{CN}$ restricted to the ventrolateral DCN and lateral PVCN. B: Photomicrographs of labeled terminal endings in the ICXV $(\times 20)$, corresponding to the region indicated by the triangle in F. C-F: Drawings of rostral to caudal $40-\mu \mathrm{m}$ trans-

verse sections across the IC. Most of the labeled terminals were found in the contralateral IC primarily in the ICXV (filled triangles) and lateral CIC. Some labeled terminals were found in the lateral ICX $(\mathrm{D}, \mathrm{E})$ and the rostral ICX (C). Each dot represents 1-3 terminal endings. Scale bars $=500 \mu \mathrm{m}$ in A; $25 \mu \mathrm{m}$ in B; $2 \mathrm{~mm}$ in $\mathrm{C}-\mathrm{F}$. 


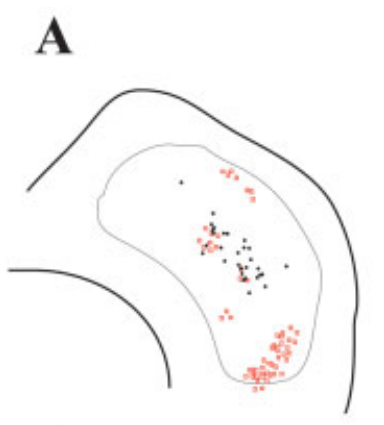

C

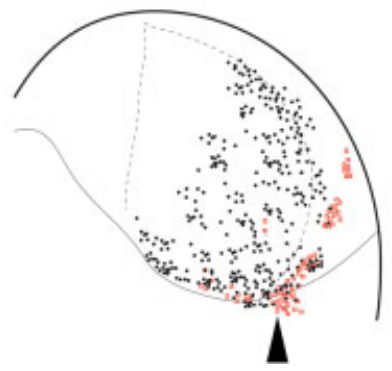

Fig. 7. Overlap of drawings of the Sp5 terminations with those of the CN terminations in the IC. A-D: Rostral to caudal sequence. Red squares represent the Sp5 terminations and black dots represent the $\mathrm{CN}$ terminations. Most of the convergence was observed in the ICXV (triangles in C,D) and some convergence in the rostral ICX. Each dot/square represents $1-3$ terminal endings. Scale bar $=2 \mathrm{~mm}$ in $\mathrm{B}$ (applies to A-D).

endings could be found in the ICXV, lateral ICX, as well as the rostral ICX. The ICXV is the region receiving the most dense projections from Sp5. In agreement with earlier findings (Oliver, 1984; Willard and Martin, 1983; Thompson, 1998), CN terminations in the ICX were en passant or small terminal boutons.

\section{Convergence of $\mathrm{CN}$ and $\mathrm{Sp5}$ projections to the IC}

The ICX receives a broad spectrum of somatosensory inputs from Sp5 (Coleman and Clerici, 1987; Kunzle, 1998; present study), spinal cord and dorsal column nuclei (Aitkin, 1978; Morest and Oliver, 1984; Coleman and Clerici, 1987; Paloff and Usunoff, 1992; Kunzle, 1993). In addition to auditory inputs from the CN (Ryugo et al., 1981; Aitkin et al., 1981; Oliver, 1984; Coleman and Clerici, 1987; Oliver et al., 1999), the ICX receives input from the lateral superior olive (Loftus et al., 2004), CIC (Saldana and Merchan, 1992), and auditory cortex (Bajo and Moore, 2005). The ICX is therefore ideally situated for multimodal integration (Aitkin et al., 1978, 1981; Paloff and Usunoff, 1992; Malmierca et al., 2002). Since the ICXV is a region receiving auditory inputs primarily from ascending auditory pathways, it can be considered a primary region of ICX for processing multisensory information. The overlap of terminal endings in the ICXV from both $\mathrm{CN}$ and Sp5 provides the first anatomical substrate for multimodal integration in this region of ICX.
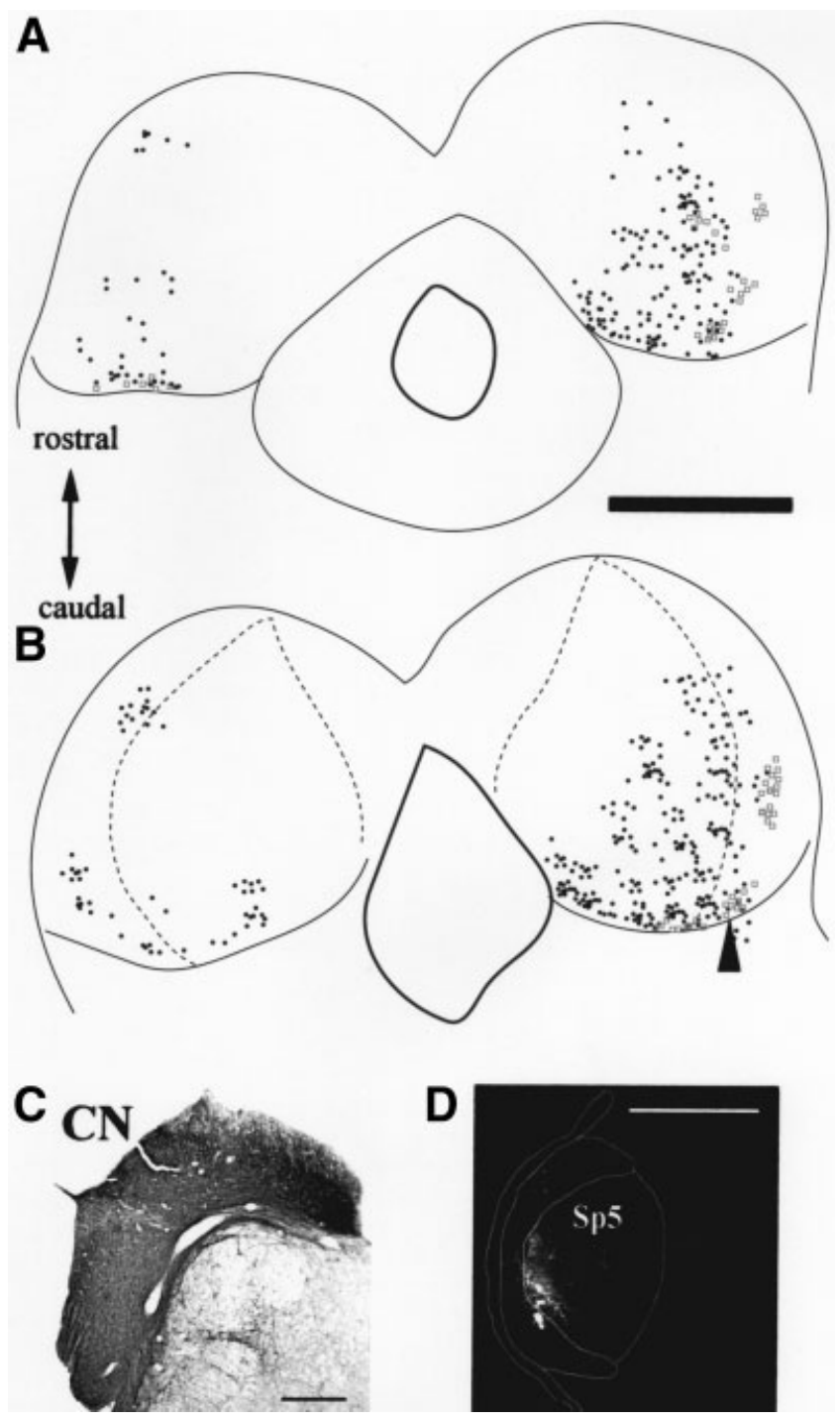

Fig. 8. Anterograde terminal labeling in the IC following dual injections in both left CN and Sp5 (subject 090904). Red squares represent the Sp5 terminations and black dots represent the $\mathrm{CN}$ terminations. Convergence was mostly observed in the ICXV (filled triangle), and some in the rostral IC. Injection sites in both $\mathrm{CN}$ and Sp5 are shown in the bottom photomicrographs. Each dot/square represents $1-3$ terminal endings. Scale bars $=2 \mathrm{~mm}$ in A (applies to $\mathrm{A}, \mathrm{B}) ; 500 \mu \mathrm{m}$ in $\mathrm{C} ; 1 \mathrm{~mm}$ in $\mathrm{D}$.

Neurons in the ICX (including ICXV) respond to both acoustic and tactile stimuli (Aitkin et al., 1978, 1981). In some ICX neurons Sp5 stimulation can modulate sound-evoked responses in ICX neurons, even when Sp5 stimulation alone does not evoke responses (Jain and Shore, 2004; Shore, 2005b). This suppression of soundevoked activity by somatosensory stimulation is also evident in neurons of the ectosylvian cortex (Dehner et al., 2004), and the DCN (Shore, 2005a), the latter projecting to the ICX. Multimodal integration in the ICX may therefore play a role in the cancellation of selfgenerated sounds. Sounds associated with chewing, vocalization, and respiration may be suppressed by the 


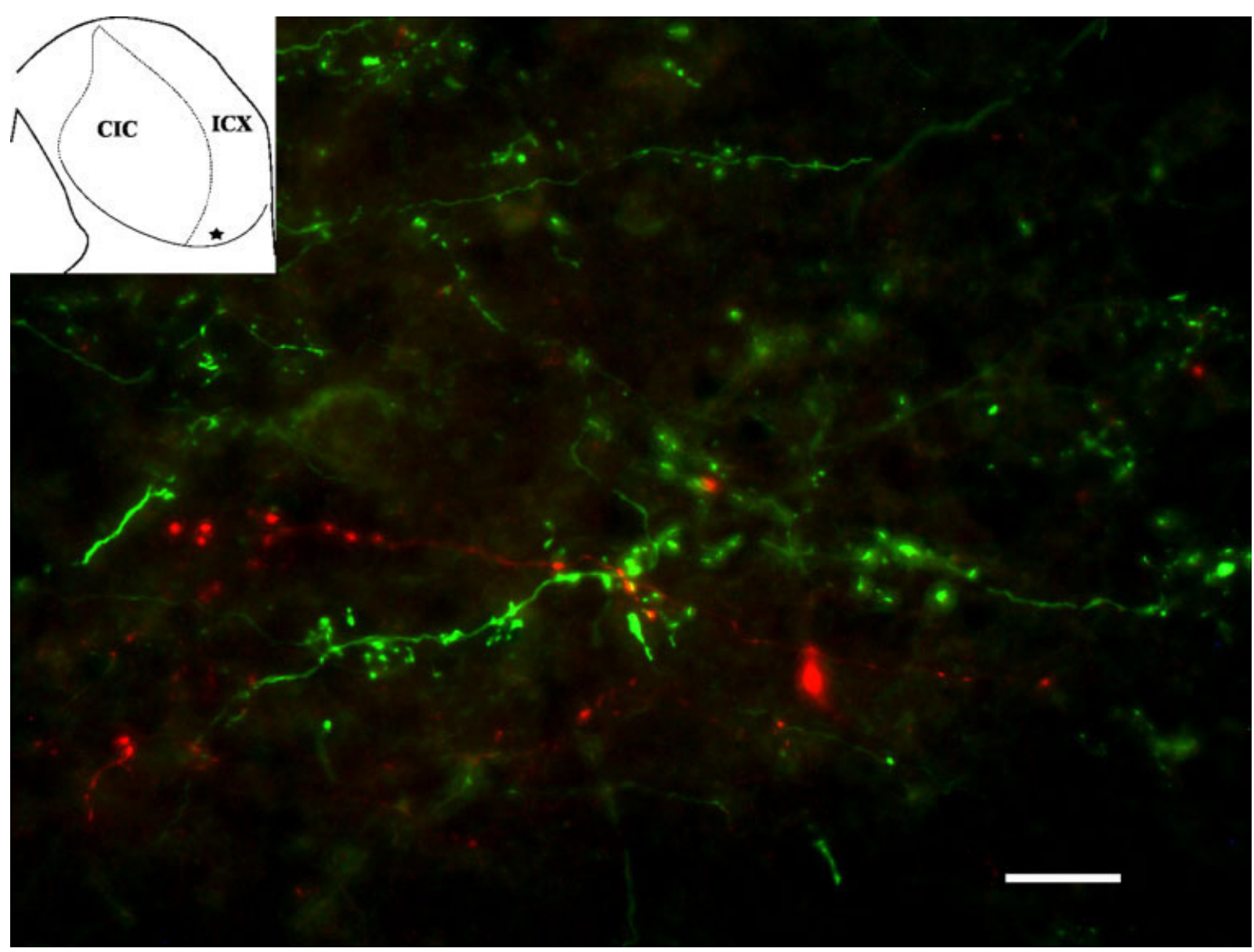

Fig. 9. Photomicrograph $(\times 20)$ of terminal endings in the right ICXV after double injections of FR into the left Sp5I (red) and BDA into the left CN (green). The inset drawing (star) indicates the region of the photomicrograph. The terminal endings from the two sensory systems had similar morphological appearances. Scale bar $=10 \mu \mathrm{m}$.

concurrent activity from the somatosensory system, which likely originates in the proprioceptive afferents or broad dynamic range mechanoceptors in deep tissues.

Studies in monkeys support the hypothesis that the ICXV plays a role in the suppression of self-generated vocalizations. Neurons in the ICXV show a differential response to the vocalizations of other monkeys versus self-produced vocalizations: External vocalizations produce a vigorous response, while self-produced vocalizations suppress the responses in these neurons (Tammer et al., 2004). Anatomical evidence also supports this hypothesis, since the dorsomedial and marginal subdivisions of Sp5I and Sp5C receive somatosensory inputs from vocal structures and, in turn, project to the ICXV (Romfh et al., 1979; Capra, 1987; Nazruddin et al., 1989; Takemura et al., 1991; Suemune et al., 1992).

\section{LITERATURE CITED}

Abercrombie M. 1946. Estimation of nuclear population from microtome sections. Anat Rec 94:239-245.

Aitkin LM, Webster WR, Veale JL, Crosby DC. 1975. Inferior colliculus. I. Comparison of response properties of neurons in central, pericentral, and external nuclei of adult cat. J Neurophysiol 38:1196-1207.
Aitkin LM, Dickhaus H, Schult W, Zimmermann M. 1978. External nucleus of inferior colliculus: auditory and spinal somatosensory afferents and their interactions. J Neurophysiol 41:837-847.

Aitkin LM, Kenyon CE, Philpott P. 1981. The representation of the auditory and somatosensory systems in the external nucleus of the cat inferior colliculus. J Comp Neurol 196:25-40.

Aitkin L, Tran L, Syka J. 1994. The responses of neurons in subdivisions of the inferior colliculus of cats to tonal, noise and vocal stimuli. Exp Brain Res 98:53-64.

Bajo VM, Moore DR. 2005. Descending projections from the auditory cortex to the inferior colliculus in the gerbil, Meriones unguiculatus. J Comp Neurol 486:101-116.

Cant NB. 1982. Identification of cell types in the anteroventral cochlear nucleus that project to the inferior colliculus. Neurosci Lett 32:241246.

Capra NF. 1987. Localization and central projections of primary afferent neurons that innervate the temporomandibular joint in cats. Somatosens Res 4:201-213.

Coleman JR, Clerici WJ. 1987. Sources of projections to subdivisions of the inferior colliculus in the rat. J Comp Neurol 262:215-226.

Darian-Smith I. 1973. The trigeminal system. In: Iggo A, editor. Handbook of sensory physiology. Somatosensory system. Berlin: Springer. p 271314 .

Dehner LR, Keniston LP, Clemo HR, Meredith MA. 2004. Cross-moda circuitry between auditory and somatosensory areas of the cat anterior ectosylvian sulcal cortex: a 'new' inhibitory form of multisensory convergence. Cereb Cortex 14:387-403. 
Faye-Lund H, Osen KK. 1985. Anatomy of the inferior colliculus in rat. Anat Embryol (Berl) 171:1-20.

FitzPatrick KA. 1975. Cellular architecture and topographic organization of the inferior colliculus of the squirrel monkey. J Comp Neurol 164 185-207.

Gordon M, O’Neill WE. 1998. Temporal processing across frequency channels by FM selective auditory neurons can account for FM rate selectivity. Hear Res 122:97-108.

Gordon M, O'Neill WE. 2000. An extralemniscal component of the mustached bat inferior colliculus selective for direction and rate of linear frequency modulations. J Comp Neurol 426:165-181.

Groff JA, Liberman MC. 2003. Modulation of cochlear afferent response by the lateral olivocochlear system: activation via electrical stimulation of the inferior colliculus. J Neurophysiol 90:3178-3200.

Hayashi H, Sumino R, Sessle BJ. 1984. Functional organization of trigeminal subnucleus interpolaris: nociceptive and innocuous afferent inputs, projections to thalamus, cerebellum, and spinal cord, and descending modulation from periaqueductal gray. J Neurophysiol 51: $890-905$.

Henkel CK, Brunso-Bechtold JK. 1993. Laterality of superior olive projections to the inferior colliculus in adult and developing ferret. J Comp Neurol 331:458-468.

Jacquin MF, Woerner D, Szczepanik AM, Riecker V, Mooney RD, Rhoades RW. 1986. Structure-function relationships in rat brainstem subnucleus interpolaris. I. Vibrissa primary afferents. J Comp Neurol 243:266-279.

Jacquin MF, Stennett RA, Renehan WE, Rhoades RW. 1988. Structurefunction relationships in the rat brainstem subnucleus interpolaris. II Low and high threshold trigeminal primary afferents. J Comp Neurol 267:107-130

Jacquin MF, Renehan WE, Rhoades RW, Panneton WM. 1993. Morphology and topography of identified primary afferents in trigeminal subnuclei principalis and oralis. J Neurophysiol 70:1911-1936.

Jain R, Shore S. 2004. The external nucleus of inferior colliculus integrates somatosensory and acoustic information. Association for Research in Otolaryngology (ARO), Abstract 416.

Knudsen EI. 1983. Subdivisions of the inferior colliculus in the barn owl (Tyto alba). J Comp Neurol 218:174-186.

Kunzle H. 1993. Tectal and related target areas of spinal and dorsal column nuclear projections in hedgehog tenrecs. Somatosens Mot Res 10:339-353.

Kunzle H. 1998. Origin and terminal distribution of the trigeminal projections to the inferior and superior colliculi in the lesser hedgehog tenrec. Eur J Neurosci 10:368-376.

Li H, Mizuno N. 1997. Single neurons in the spinal trigeminal and dorsal column nuclei project to both the cochlear nucleus and the inferior colliculus by way of axon collaterals: a fluorescent retrograde doublelabeling study in the rat. Neurosci Res 29:135-142.

Loftus WC, Bishop DC, Saint Marie RL, Oliver DL. 2004. Organization of binaural excitatory and inhibitory inputs to the inferior colliculus from the superior olive. J Comp Neurol 472:330-344.

Malmierca MS, Merchan MA, Henkel CK, Oliver DL. 2002. Direct projections from cochlear nuclear complex to auditory thalamus in the rat. J Neurosci 22:10891-10897.

Morest DK, Oliver DL. 1984. The neuronal architecture of the inferior colliculus in the cat: defining the functional anatomy of the auditory midbrain. J Comp Neurol 222:209-236.

Nazruddin, Suemune S, Shirana Y, Yamauchi K, Shigenaga Y. 1989. The cells of origin of the hypoglossal afferent nerves and central projections in the cat. Brain Res 490:219-235.

Oliver DL. 1984. Dorsal cochlear nucleus projections to the inferior colliculus in the cat: a light and electron microscopic study. J Comp Neurol 224:155-172.

Oliver DL. 1987. Projections to the inferior colliculus from the anteroventral cochlear nucleus in the cat: possible substrates for binaural interaction. J Comp Neurol 264:24-46.

Oliver DL. 2005. Neuronal organization in the inferior colliculus. In: Jeffery A, Winer CES, editors. The inferior colliculus. Berlin: Springer.

Oliver DL, Beckius GE, Shneiderman A. 1995. Axonal projections from the lateral and medial superior olive to the inferior colliculus of the cat: a study using electron microscopic autoradiography. J Comp Neurol 360 . $17-32$.

Oliver DL, Beckius GE, Bishop DC, Kuwada S. 1997. Simultaneous anterograde labeling of axonal layers from lateral superior olive and dorsal cochlear nucleus in the inferior colliculus of cat. J Comp Neurol 382:215-229.
Oliver DL, Ostapoff EM, Beckius GE. 1999. Direct innervation of identified tectothalamic neurons in the inferior colliculus by axons from the cochlear nucleus. Neuroscience 93:643-658.

Osen KK. 1972. Projection of the cochlear nuclei on the inferior colliculus in the cat. J Comp Neurol 144:355-372.

Ota Y, Oliver DL, Dolan DF. 2004. Frequency-specific effects on cochlear responses during activation of the inferior colliculus in the guinea pig. J Neurophysiol 91:2185-2193.

Paloff AM, Usunoff KG. 1992. Projections to the inferior colliculus from the dorsal column nuclei. An experimental electron microscopic study in the cat. J Hirnforsch 33:597-610.

Popelar J, Syka J. 1982. Response properties of neurons in the inferior colliculus of the guinea-pig. Acta Neurobiol Exp (Wars) 42:299-310.

Romfh JH, Capra NF, Gatipon GB. 1979. Trigeminal nerve and temporomandibular joint of the cat: a horseradish peroxidase study. Exp Neurol 65:99-106.

Ryugo DK, Willard FH, Fekete DM. 1981. Differential afferent projections to the inferior colliculus from the cochlear nucleus in the albino mouse. Brain Res 210:342-349.

Saldana E, Merchan MA. 1992. Intrinsic and commissural connections of the rat inferior colliculus. J Comp Neurol 319:417-437.

Schofield BR, Cant NB. 1996. Projections from the ventral cochlear nucleus to the inferior colliculus and the contralateral cochlear nucleus in guinea pigs. Hear Res 102:1-14.

Shigenaga Y, Okamoto T, Nishimori T, Suemune S, Nasution ID, Chen IC, Tsuru K, Yoshida A, Tabuchi K, Hosoi M, et al. 1986. Oral and facial representation in the trigeminal principal and rostral spinal nuclei of the cat. J Comp Neurol 244:1-18.

Shneiderman A, Henkel CK. 1987. Banding of lateral superior olivary nucleus afferents in the inferior colliculus: a possible substrate for sensory integration. J Comp Neurol 266:519-534.

Shore S. 2005a. Multisensory integration in the dorsal cochlear nucleus: Responses to acoustic and trigeminal stimulation. Eur J Neurosci 21:3334-3348.

Shore SE. 2005b. Tinnitus: theory and management. In: Snow J, editor Tinnitus: theory and management. London: BC Decker. p 125-141.

Shore SE, Moore JK. 1998. Sources of input to the cochlear granule cell region in the guinea pig. Hear Res 116:33-42.

Suemune S, Nishimori T, Hosoi M, Suzuki Y, Tsuru H, Kawata T, Yamauchi K, Maeda N. 1992. Trigeminal nerve endings of lingual mucosa and musculature of the rat. Brain Res 586:162-165.

Suta D, Kvasnak E, Popelar J, Syka J. 2003. Representation of speciesspecific vocalizations in the inferior colliculus of the guinea pig. J Neurophysiol 90:3794-3808.

Syka J, Popelar J, Kvasnak E, Astl J. 2000. Response properties of neurons in the central nucleus and external and dorsal cortices of the inferior colliculus in guinea pig. Exp Brain Res 133:254-266.

Takemura M, Sugimoto T, Shigenaga Y. 1991. Difference in central projection of primary afferents innervating facial and intraoral structures in the rat. Exp Neurol 111:324-331.

Tammer R, Ehrenreich L, Jurgens U. 2004. Telemetrically recorded neuronal activity in the inferior colliculus and bordering tegmentum during vocal communication in squirrel monkeys (Saimiri sciureus). Behav Brain Res 151:331-336.

Thompson AM. 1998. Heterogeneous projections of the cat posteroventral cochlear nucleus. J Comp Neurol 390:439-453.

Usunoff KG, Marani E, Schoen JH. 1997. The trigeminal system in man. Adv Anat Embryol Cell Biol 136:I-X, 1-126.

Vercelli A, Repici M, Garbossa D, Grimaldi A. 2000. Recent techniques for tracing pathways in the central nervous system of developing and adult mammals. Brain Res Bull 51:11-28.

Wagner H, Gunturkun O, Nieder B. 2003. Anatomical markers for the subdivisions of the barn owl's inferior-collicular complex and adjacent peri- and subventricular structures. J Comp Neurol 465:145-159.

Wiberg M, Westman J, Blomqvist A. 1987. Somatosensory projection to the mesencephalon: an anatomical study in the monkey. J Comp Neurol 264:92-117.

Willard FH, Martin GF. 1983. The auditory brainstem nuclei and some of their projections to the inferior colliculus in the North American opossum. Neuroscience 10:1203-1232.

Zhou J, Shore S. 2004. Projections from the trigeminal nuclear complex to the cochlear nuclei: a retrograde and anterograde tracing study in the guinea pig. J Neurosci Res 78:901-907. 